\title{
Metabolite cycling indicated by long-range correlation in a sediment bioreactor mixed microbial community
}

\author{
Allison M. L. Enright ${ }^{1 *}$, Christopher T. Parsons², Mihaela Glamoclija ${ }^{1}$ \\ 1. Department of Earth and Environmental Sciences, Rutgers University, 101 Warren St. Newark, \\ NJ, 07029 \\ 2. Ecohydrology Research Group, Department of Earth and Environmental Sciences, University of \\ Waterloo, 200 University Avenue West, Waterloo, ON, Canada N2L 3G1
}

Corresponding author: Allison Enright (allison.enright@rutgers.edu)

\section{Key Points:}

- Fluctuation analysis of geochemical time series provide information about ongoing biogeochemical processes

- Interpreting geochemical time series collectively can distinguish dominant geochemical processes

- Time series analysis of data sets from geophysical sensors may indicate specific biogeochemical processes 


\begin{abstract}
Geophysical surveys add value to biogeochemical studies because of their ability to characterize systems remotely, and their precise time resolution. One limitation, however, is their lack of biogeochemical process specificity. Here, electrochemical time series from an oxic-anoxic cyclical bioreactor experiment were reanalyzed with detrended fluctuation analysis (DFA) to distinguish dominant biogeochemical processes. Measurements of $\mathrm{E}_{\mathrm{H}}, \mathrm{pH}$, dissolved oxygen (DO) were recorded every 20 minutes for 74 days. The time series were divided by geochemical environment (aerobic respiration, $\mathrm{NO}_{3}{ }^{-}$reduction, mixed $\mathrm{Fe}(\mathrm{III}), \mathrm{Mn}(\mathrm{IV}), \mathrm{SO}_{4}{ }^{2-}$ reduction, and anoxic-oxic transition), and analyzed for correlation strength using DFA. Correlation strength varied systematically by environment over five oxic-anoxic cycles. This repetition makes it clear that electrode fluctuations are not random, nor are they noise. In fact, electrode fluctuations are a system-specific measurement of dominant geochemical conditions. The results of this study in a well-constrained environment with a complex microbial community support the potential to use galvanic and electrochemical approaches to remediation as a viable, cost-effective, and simple long-term monitoring strategy. The information provided by time series analysis requires no special sensors or additional data collection, just a short computational analysis for new, valuable information about ongoing geochemical reactions. This approach could be valuable in any application where remote, long-term monitoring of ongoing biogeochemical processes is desirable, such as agriculture, bioreactors, or in long-term remediation and monitoring programs where inexpensive, consistent data sets could provide valuable insight into degradation and environmental stability.
\end{abstract}




\section{Plain Language Summary}

Geophysical surveys are valuable in biogeochemical studies because of their ability to study the subsurface remotely, and their precise time resolution. One limitation, however, is that geophysics detects the environmental changes that result from processes, not the processes themselves. Resolving these questions requires additional geochemical and microbiological data, which is time consuming and expensive in comparison to geophysical techniques. This paper presents a new method of electrochemical data analysis, detrended fluctuation analysis (DFA), which uses sensors which are already common for soil science, biogeochemistry, and hydrology. Here we demonstrate how DFA can distinguish between different geochemical processes using only electrochemical measurements, which resolves the existing limitation of electrode-based geophysical approaches. This method requires only minimal additional data collection, and the processing can be accomplished in less than a day on a desktop computer. This approach could be valuable in any application where remote, long-term monitoring of ongoing biogeochemical processes is desirable, such as agriculture, bioreactors, or in long-term remediation and monitoring programs where inexpensive, consistent data sets could provide valuable insight into degradation and environmental stability. 


\section{Introduction}

Geophysical techniques have become a valuable supplement to geochemical and microbiological analyses [Atekwana and Atekwana, 2009; Beaver et al., 2015; Lund et al., 2017; Mellage et al., 2018; Kenneth H. Williams et al., 2010] due to the many changes in physical and chemical properties which microbial activity induces within its environment. Several mechanisms have been proposed to account for the observed changes in geophysical responses with the onset of biological activity. These include: (1) microbially-induced mineral dissolution and precipitation [Eliot A. Atekwana et al., 2004; Estella A. Atekwana et al., 2004a; Estella A. Atekwana et al., 2004b; Ntarlagiannis et al., 2005b; Personna et al., 2008; K. H. Williams et al., 2005]; (2) porosity changes due to the attachment of microbial cells to sediment grains and precipitation of biomaterials such as extracellular polymeric substances [G Z Abdel Aal et al., 2004; Davis et al., 2006; Ntarlagiannis et al., 2005a]; and (3) redox processes [Beaver et al., 2015; Naudet and Revil, 2005; Kenneth H. Williams et al., 2007].

Geophysical techniques offer a number of advantages which make them effective supplements to microbiological and geochemical analysis, especially in field studies. Specifically, the use of geophysical surveys is a powerful method of delineating geochemical boundaries and identifying hot spots of microbial activity remotely and quickly [Beaver et al., 2015] to guide sampling efforts and ensure representative geochemical conditions have been accurately sampled. Geophysical techniques are minimally invasive, capable of the remote identification of subsurface biogeochemical transformations [Naudet and Revil, 2005; Naudet et al., 2003; Naudet et al., 2004; Kenneth H. Williams et al., 2010], suitable for long-term deployment, and offer higher spatial and temporal resolution. In addition, geophysical data processing is generally more rapid, reducing the time between implementation of a remediation strategy and evaluating its effectiveness dramatically [Kenneth H. Williams et al., 2010].

The self-potential (SP) technique is well-established as an inexpensive and sensitive means of delineating variations in surficial or subsurface geochemical conditions resulting from both abiotic [Cameron et al., 2004; Corry, 1985] and biotic processes [Naudet and Revil, 2005; Naudet et al., 2003; Nyquist and Corry, 2002]. The SP method is a passive technique that measures the open- 
circuit potential between electrodes, located either at ground surface or within boreholes. The potential-generating mechanism varies according to environment and measurement conditions. Generally, however, these anomalies generally arise from two electrochemical half-cell reactions occurring in different locations, each with a different redox state being electrically connected, collectively constituting a galvanic cell [Kenneth H. Williams et al., 2010]. The term "biogeobattery" describes SP anomalies resulting from microbial processes [G Abdel Aal et al., 2009; Naudet and Revil, 2005; Naudet et al., 2003]. Many different half-cell pairs can give rise to both SP anomalies in general, and biogeobatteries specifically [G Abdel Aal et al., 2009; Revil et al., 2010].

When the contributing half-cell reactions chemically involve the electrode, the measurement is described as electrodic potential (EP) [Nyquist and Corry, 2002; Kenneth H. Williams et al., 2007; Kenneth H. Williams et al., 2010]. In this case, the electrode material determines the nature of the measured half-cell reaction, and the magnitude of the potential may be quantitatively interpreted in the same manner as ion-selective electrodes [Kenneth H. Williams et al., 2010]. If an EP signal is the result of a galvanic effect where the measurement electrode acts as a nonreactive surface, the measurement electrode serves the same function as the platinum electrode in an oxidation reduction potential (ORP) probe [Kenneth H. Williams et al., 2010]. Spatiotemporal variations in the onset and sustenance of the EP anomalies appear to track the location of active metabolism within the aquifer, offering an indirect means for verifying geochemically reduced conditions conducive to the removal of aqueous uranium [Kenneth H. Williams et al., 2010].

To date, one major drawback of geophysical approaches has been their lack of process specificity. Without a priori knowledge of the geochemical environment and ongoing biological processes, it was not possible to conclusively link a specific biological process to the measured geophysical response. Recently, fluctuation analysis of redox potential time series were used to distinguish microbial and abiotic iron oxidation in a high- and low-biomass sections of a bioreactor [Allison M. L. Enright and F. Grant Ferris, 2016], and a series of chemically-similar microcosms [Allison M. L. Enright and F. G. Ferris, 2016]. Fluctuation analysis encompasses a suite of time-domain signal processing techniques which evaluates the strength of correlation in time series. The 
physical meaning of correlation is related to the diffusion of electrode-sensitive ions in solution [Metzler and Klafter, 2000].

This presents an opportunity to consider a new dimension of geophysical data processing; could fluctuation analysis of geochemical time series identify the dominant biogeochemical processes without relying on supplemental microbiological and geochemical analyses? Coupled with wellestablished electrochemical techniques by determining both the concentration and ion flux, a robust geochemical understanding could be gleaned from electrodes alone. Here, a wellconstrained data set of geochemical time series $\left(\mathrm{pH}\right.$, redox potential, and dissolved $\mathrm{O}_{2}(\mathrm{DO})$ ) from an oxic-anoxic cyclical bioreactor experiment [Parsons et al., 2017], was reanalyzed using detrended fluctuation analysis (DFA) to determine if the suite of measurements could act as a geophysical fingerprint for a specific, dominant geochemical environment.

\section{Materials and Methods}

\subsection{Bioreactor Experiments}

The bioreactor experiments are described in detail in [Parsons et al., 2017]. All geochemical data analyzed here are presented in the main text or supplemental material. For context, we have briefly summarized relevant aspects of the experimental procedure. A 1 L sediment suspension collected from a hyper-eutrophic, coastal freshwater marsh was inoculated into a bioreactor. After an initial 11 day equilibration period, the suspension was subjected to 7- day periods of sparging (30 $\mathrm{mL}$

$\left.\min ^{-1}\right)$, alternating between $\mathrm{N}_{2}: \mathrm{CO}_{2}\left(1 \% \mathrm{CO}_{2}\right)$ and $\mathrm{O}_{2}: \mathrm{N}_{2}: \mathrm{CO}_{2}$. The suspension was kept at constant temperature $\left(25^{\circ} \mathrm{C}\right)$ in the dark, and stirred continuously at $500 \mathrm{rpm}$.

\subsubsection{Time Series Data}

$\mathrm{E}_{\mathrm{H}}, \mathrm{pH}$, and DO (\% saturation) were measured at 20-minute intervals for the duration of the experiment, using a combined autoclavable Mettler Toledo InPro 3252i/SG open-junction electrode ( $\mathrm{E}_{\mathrm{H}}, \mathrm{pH}$, temperature), and an AppliSens Low drift polarographic sensor (DO). The InPro electrode system uses a common reference electrode to avoid interference induced by multiple 
electrodes in close proximity. DO was calibrated using $100 \%$ saturation in air $(\sim 0.2905 \mathrm{~atm})$ and $0 \%$ saturation in $\mathrm{N}_{2} . \mathrm{NO}_{2}{ }^{-}, \mathrm{NO}_{3}{ }^{-}, \mathrm{Fe}(\mathrm{II}), \mathrm{S}^{-}, \mathrm{SO}_{4}{ }^{2-}$, and $\mathrm{Mn}(\mathrm{II})$ measurements were made at least every two days to assess ongoing metabolic reactions. $\mathrm{CO}_{2}$ was measured in the gas output from the reactor headspace with a BlueSens IR $\mathrm{CO}_{2}$ sensor, every 20 minutes.

After the 11-day aerobic equilibration period, ionic strength of the aqueous phase in the reactor suspension remained at $\sim 0.025 \pm 0.004 \mathrm{M}$ for the duration of the experiment [Parsons et al., 2017]. $\mathrm{pH}$ oscillated from $\sim 7.7$ (oxic) to $\sim 7.4$ (anoxic), and was generally consistent across all five cycles. The oscillations were largely driven by changes in $\mathrm{CO}_{2}$ concentration. Aqueous chemistry data confirmed that terminal electron acceptors are consumed in order of decreasing energetic yield, coupled to the oxidation of labile organic matter [Parsons et al., 2017].

\subsection{Time series analysis}

The 74-day long $(n=5330)$ time series were initially cut into aerobic and anaerobic periods based on the time of changes of gas influx. From there, aerobic time series were divided into aerobic transition and aerobic respiration periods, and anaerobic time series were divided into $\mathrm{NO}_{3}{ }^{-}$reduction and mixed $\mathrm{Fe}(\mathrm{III}) / \mathrm{Mn}(\mathrm{IV}) / \mathrm{SO}_{4}{ }^{2-}$ - reduction periods based on the geochemical data (Figure 1). The end points of each time series were verified with change point analysis (MatLAB). The initial 11-day aerobic equilibration period, as well as time series where $\mathrm{n}<100$ were discarded. In the first case, this is due to the establishment of conditions, rather than observation of a steady state. In the former, due to the length of scaling observed, it was not possible to capture the complete scaling range with $\mathrm{n}<100$.

\subsubsection{Fluctuation Analysis}

Fluctuation analysis techniques analyze the stochastic component of time series. The DFA algorithm [Peng et al., 1994] measures the strength of long-range correlation in time series. It was used to calculate scaling coefficients for each of the realizations. The DFA algorithm has six steps, and it was executed in MatLAB, as follows:

(1) Subtract the mean and integrate the realization according to: 


$$
y(k)=\sum_{i=1}^{k}\left[m(i)-m_{\text {avg }}\right]
$$

where $\mathrm{y}$ is the signal profile of realization $\mathrm{m}$ at index $\mathrm{k}, i$ is the index of the realization $\mathrm{m}$, and $\mathrm{m}_{\mathrm{avg}}$ is the average value of realization $\mathrm{m}$.

(2) The integrated realization is divided into $\mathrm{j}$ boxes of length $\mathrm{n}$, such that $\mathrm{k}=\mathrm{jn}$. In each box, a least squares fit is used to calculate the linear trend.

(3) For each data point, the integrated realization is subtracted from the calculated trend.

(4) The root-mean-square difference between the realization and the trend is calculated in each box.

(5) This calculation is repeated for each window of length $n$, and for many pairs of $j$ and $n$, and an average value of fluctuation, $\mathrm{F}(\mathrm{n})$ for window length $\mathrm{n}$ is determined.

(6) A double-log plot of the average fluctuation value as a function of window size, $n$, is created. If a linear relationship is observed, the realization is said to be self-similar in the time domain, and the slope is the scaling coefficient, $\alpha$.

The physical meaning of correlation strength is related to diffusion and energy degradation processes. The electrode surface represents an arbitrary area in a well-mixed system. Since the magnitude of the electrode potential represents the sum of charged species interacting with the electrode surface, the small-scale changes (fluctuations) in magnitude, measured over time, record the flux of dissolved chemical species which the electrode responds to. Time series of fluctuations measure a flux of electrode-sensitive ions, and, indirectly, the available free energy of the system which is available to perform work, through either biological or abiotic reactions. Fickian or normal diffusion has a scaling exponent $\alpha=1$. Self-diffusion, where concentration is constant throughout the system, has a scaling exponent of $\alpha=0.5$. Processes with $\alpha<1.0$ are subdiffusive [Jeon et al., 2014; Metzler and Klafter, 2000; Metzler et al., 2014], and processes with $\alpha>1.0$ are superdiffusive [Jeon et al., 2014; Metzler and Klafter, 2000; Metzler et al., 2014]. When the correlation coefficient indicates superdiffusion, the sensing ions are, on average, traversing longer random walk paths (MSD) than normally-diffusing ions under identical environmental conditions 
(too much motion or too fast), while, inversely, subdiffusion indicates that the dissolved ions, on average, are traversing shorter random walk paths than predicted by Fick's law.

\section{Results}

The three original time series, as well as the compiled signal profiles (Step 1 of DFA algorithm) are presented in Figure 1. The geochemical data is also presented as time series in Figure 1, to permit direct comparison between metabolite consumption and fluctuation analysis. Figure 2 presents representative fluctuation analysis (Step 6 of DFA). Figure 3 compares the average values for each metabolic type as well as all of the realizations.

\subsection{Aerobic Conditions}

Generally during aerobic periods, $\mathrm{E}_{\mathrm{H}}$ is relatively stable, generally varying less than $40 \mathrm{mV}$, with an average value of $428-450 \mathrm{mV}$ over the course of the seven-day period (periods $2-5$ ). $\mathrm{pH}$ was also stable with average values of 7.68. Period 5 has an anomalously high average $\mathrm{pH}$ value of 7.89. DO was consistently above $100 \%$ saturation with respect to the calibrated sensor, which is to be expected. All three geochemical time series indicate stable, steady-state conditions. Scaling behavior during aerobic respiration is characterized as follows: very strong correlation of $\mathrm{pH}$ (1.74 $\pm 0.04)$, and $\mathrm{E}_{\mathrm{H}}(1.72 \pm 0.04)$, and strong correlation of DO $(1.35 \pm 0.04)$.

\section{$3.2 \mathrm{NO}_{3}{ }^{-}-$Reducing Conditions}

Decreases to nitrate concentration coincided with peaks of nitrite concentration within the first hour of oxygen removal, indicative of microbial denitrification [Parsons et al., 2017]. Following the influx of $\mathrm{N}_{2}$, residual oxygen is consumed by aerobic respiration within $2 \mathrm{~h}$, and $\mathrm{NO}_{3}{ }^{-}$ concentration decreased in solution [Parsons et al., 2017]. Following $\mathrm{N}_{2}$ influx $\mathrm{E}_{\mathrm{H}}$ decreases by $100 \mathrm{mV}$ within $1 \mathrm{~h}$, and $\mathrm{CO}_{2}$ levels increase for $6 \mathrm{~h}$ then plateau, driven by sparging with $1 \% \mathrm{CO}_{2}$, as does $\mathrm{pH}$. During $\mathrm{NO}_{3}{ }^{-}$reduction, exponents indicate strong correlation of $\mathrm{pH}(1.22)$ and $\mathrm{E}_{\mathrm{H}}$ (1.38), and weak correlation of DO (0.82). 


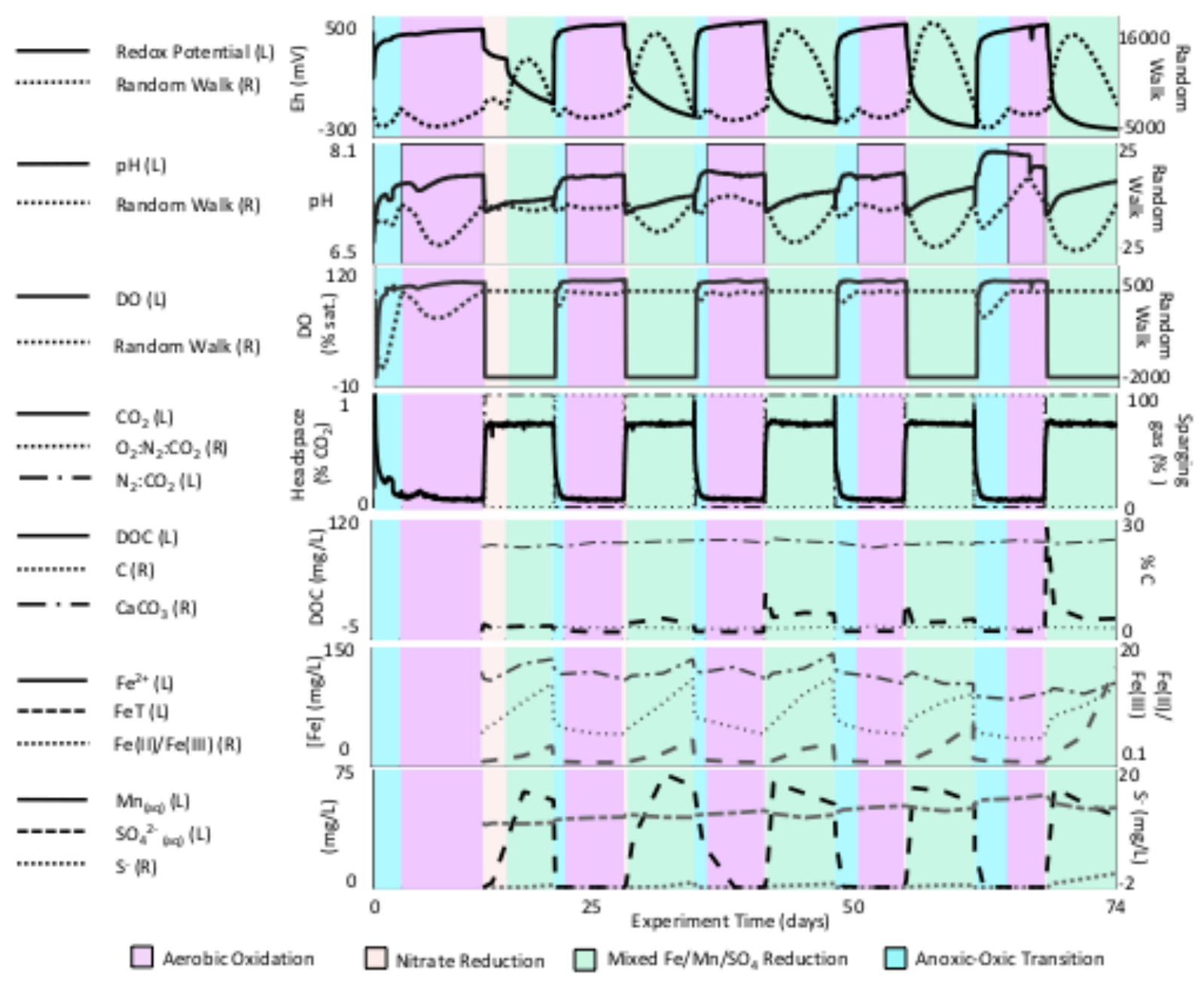

Figure 1. Long-term bioreactor experiment from a natural sediment microbial community through 5 cycles of changing metabolic activity. Blue areas indicate transitions from anaerobic to aerobic conditions, purple areas indicate aerobic oxidation, pink areas indicate periods of nitrate reduction, and green areas indicate periods of mixed $\mathrm{Mn}, \mathrm{Fe}$, and $\mathrm{SO}_{4}{ }^{2-}$ reduction. Scaling exponents were calculated for each individual period, with representative examples shown in Figure 2.

\subsection{Mixed Fe(III)/Mn(IV)/SO ${ }_{4}{ }^{2-}$ - Reducing conditions}

After the depletion of $\mathrm{NO}_{3}{ }^{-}$, the subsequent increases to $\mathrm{Mn}_{(\mathrm{aq})}, \mathrm{Fe}^{2+}$ (aq) and $\mathrm{HS}^{-}{ }_{(\text {aq })}$ imply sequential reduction of $\mathrm{MnO}_{2}, \mathrm{Fe}(\mathrm{OH})_{3}$ and $\mathrm{SO}_{4}{ }^{2-}$, as more energetically efficient electron acceptors were depleted [Parsons et al., 2017]. Mn and $\mathrm{Fe}^{2+}$ were detected in solution earlier within each subsequent anoxic cycle, however the order of reduction remained consistent across all five redox 

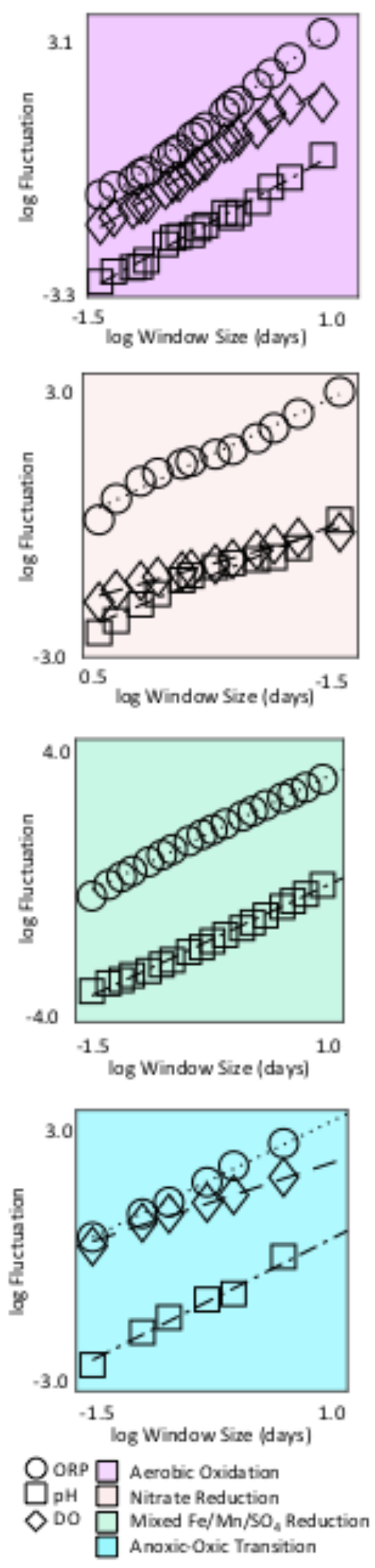

cycles $\left(\mathrm{O}_{2}, \mathrm{NO}_{3}{ }^{-}, \mathrm{NO}_{2}{ }^{-}, \mathrm{MnO}_{2}, \mathrm{Fe}(\mathrm{OH})_{3}, \mathrm{SO}_{4}{ }^{2-}\right)$ [Parsons et al., 2017]. This confirms that the main biogeochemical functioning of the sediment suspension does not change between cycles [Parsons et al., 2017]. While dissolved $\mathrm{Fe}^{2+}$ concentrations (up to $71 \mu \mathrm{M}$ ) were generally low, the $0.5 \mathrm{M} \mathrm{HCl}$ extraction to target sorbed and poorly crystalline $\mathrm{Fe}^{2+}$ indicated that extractable $\mathrm{Fe}^{2+}$ of $50-70 \mu \mathrm{mol} / \mathrm{g}$ was produced during the anoxic half-cycles [Parsons et al., 2017]. This is equivalent to 12.31 to $17.29 \mathrm{mM}$ of iron reduction for the volume of the reactor [Parsons et al., 2017].

Periods of mixed $\mathrm{Fe}(\mathrm{II}), \mathrm{Mn}^{2+}$, and $\mathrm{SO}_{4}{ }^{2-}$ reduction are characterized by reducing conditions (average $\mathrm{E}_{\mathrm{H}}=-106 \mathrm{mV}$ ), that start out only slightly reducing and progressively become more reduced, consistent with the consumption of electron acceptors. In each cycle, $\mathrm{pH}$ generally increases only slightly, $\sim 0.1 \mathrm{pH}$ units over the period, however each successive cycle has a slightly higher start and end $\mathrm{pH}$ than the cycle before. DO is entirely depleted before the onset of mix $\mathrm{Fe}(\mathrm{II}) / \mathrm{Mn} / \mathrm{SO}_{4}{ }^{2-}$ reduction. $\mathrm{CO}_{2}$ either begins above 1.0 , or reaches this value within two hours, driven by the change in sparging gas.

Each period of mixed $\mathrm{Fe}(\mathrm{II}) / \mathrm{Mn} / \mathrm{SO}_{4}{ }^{2-}$ has a very strong correlation of $\mathrm{pH}(1.67 \pm 0.02)$ and $\mathrm{E}_{\mathrm{H}}(1.77 \pm 0.02)$. Since DO was consistently measured as 0 , which is expected for anoxic conditions, mathematically this results in perfect correlation, but has no physical meaning. For this reason, it has been removed from analysis here.

\subsection{Anoxic - oxic Transitional Conditions}

Figure 2: Representative fluctuation analysis for each of the four geochemical environments identified. Each geochemical environment is characterized by specific correlation/fluctuation characteristics, which were consistent across all five cycles. 
Anoxic-oxic transitions are characterized by major changes in most geochemical parameters. $\mathrm{E}_{\mathrm{H}}$ increases $>300 \mathrm{mV}$ in each period, from less than $100 \mathrm{mV}$ to $<400 \mathrm{mV}$. $\mathrm{O}_{2}$ saturation increases to $68.5 \%$ within $1 \mathrm{~h}$ of $\mathrm{N}_{2}$ - air transition, and to above $95 \%$ within $5 \mathrm{~h}$. $\mathrm{pH}$ increases from 7.2 to 7.6 within $14 \mathrm{~h}$, and $\mathrm{CO}_{2}$ decreases from $>1.0$ to $<0.05$, driven by the sparging gas.

For $\mathrm{E}_{\mathrm{H}}$, the scaling exponent for the first period is $1.63,1.58$ for the fourth, and 1.41 for the fifth. For $\mathrm{pH}$, the first period is characterized by a scaling exponent of 1.69 , while the fourth and fifth periods have scaling exponents of 1.47 and 1.48, respectively. For dissolved oxygen, the first transitional period is characterized by extremely strong scaling with an exponent of 1.74 . The fourth and fifth periods have exponents of 0.91 and 0.95 , respectively, very close to the expected value for normal diffusion.

\section{Discussion}

Changes in redox potential within natural systems indicate the changing availability of electron acceptors, which, in turn, necessitate changes in microbial metabolic strategies [DeAngelis et al., 2010].The goal of this study was to determine if the characteristics of time series electrochemical measurements varied systematically with geochemical environment, such that a method existed which could quantify the link between changing redox state and biogeochemical environment. The scaling exponents for each time series reported here is presented in Figure 2. In Figure 3, bar graphs are used to summarize the average scaling exponents divided by environment. It is clear that there are systematic differences in scaling exponents for each period identified above (aerobic respiration, $\mathrm{NO}_{3}{ }^{-}$- reduction, mixed $\mathrm{Fe}(\mathrm{II}) / \mathrm{Mn} / \mathrm{SO}_{4}{ }^{2-}$ - reduction, and anoxic to oxic transitional). Previously, time series of redox potential have been used to infer changes in microbial community structure [DeAngelis et al., 2010; van Bochove et al., 2002], but the dynamical aspects of electrode processes had not been considered. Additionally, scaling exponents $>1.60$ have been linked to active biological cycling of electrolytes [Allison M. L. Enright and F. G. Ferris, 2016; Allison M. L. Enright and F. Grant Ferris, 2016]. Interpreted collectively, it is possible to distinguish the dominant geochemical process on the basis of electrode response. 

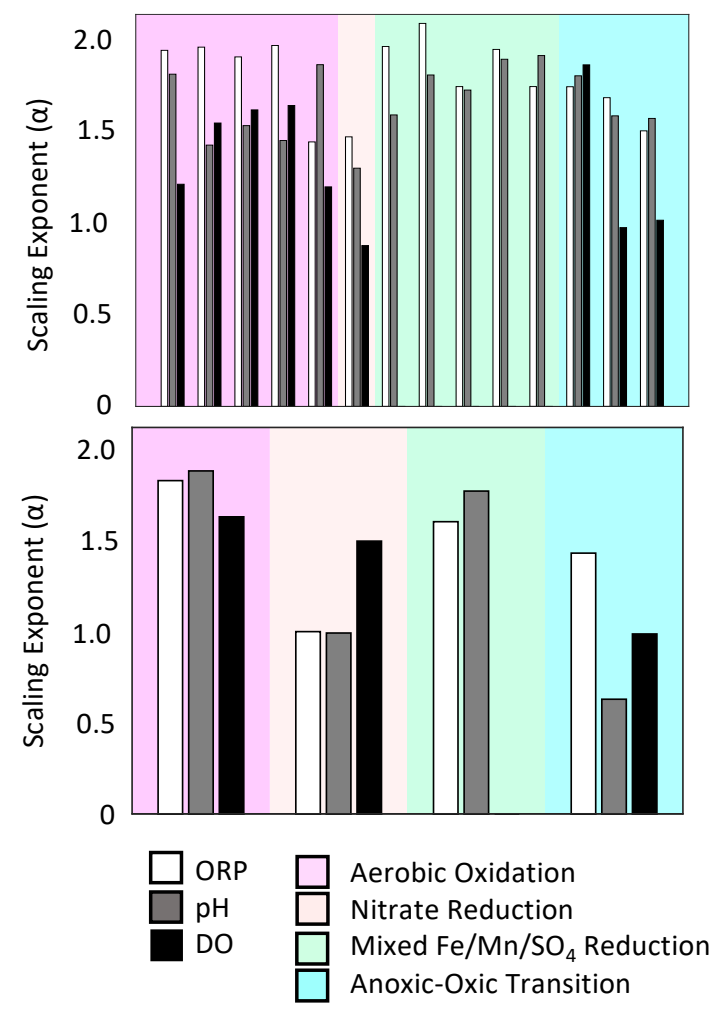

Figure 3: Bar graph summarizing scaling exponents for all time series with $\mathrm{n}>100$. Grey background: Aerobic respiration. Blue background: Mixed Fe(III), Mn(IV), SO42reduction. Green background: anoxic-oxic transition. Orange Background: Nitrate reduction.

\subsection{Relevance to Field Settings}

Electrochemical measurements have long been common in soil science, biogeochemical, remediation and hydrological settings. Electrodes are suitable for long-term deployment and their variations in their properties are widely used in field research. In the field of biogeophysics, electrodes have been used to infer changes in microbial community structure [van Bochove et al., 2002], ongoing uranium biodegredation [Kenneth H. Williams et al., 2010], and microbial sulfate reduction [Kenneth H. Williams et al., 2007]. The new information provided by time series analysis does not require any differences in sensor use or data collection; it simply requires a short computational analysis for new, valuable information. With the ability to quickly and reliably identify specific biogeochemical processes in situ, this approach may solve the

longstanding challenge in remediation efforts to quickly evaluate the utility of a particular approach. Kenneth H. Williams et al. [2010], indicated that electrodes could detect electrochemical interactions in field settings at scales exceeding $10 \mathrm{~m}$, making this approach a viable supplement to current techniques.

Monitored natural attenuation is often the method of choice for hydrocarbon contaminated sites, especially for those which do not pose an immediate risk to drinking water supplies. It may take decades for the hydrocarbons to be eliminated by natural biodegradation [Essaid et al., 2011], meaning that long-term approaches to management of these sites are necessary. The development 
of inexpensive and rapid technologies for monitoring the progress of natural attenuation, such as fluctuation analysis, is therefore a matter of critical importance.

\section{Conclusion}

The results of this study in a well-constrained environment with a complex microbial community support the potential to use galvanic and electrochemical approaches to remediation as a viable, cost-effective, and simple long-term monitoring strategy. Moreover, the changes in correlation structure which are repeated over the five oxic-anoxic cycles make it clear that electrode fluctuations are not random, nor are they noise, and in fact, are a system-specific measurement of dominant geochemical conditions.

\section{Acknowledgements and Data}

AE and MG acknowledge funding from NASA ASTEP grant NNX14AT28G. CTP acknowledges funding from the Canadian Excellence Research Chair (CERC) program to P. Van Cappellen. All data used in this analysis are already publicly available in the original publication, doi: 10.5194/bg14-3585-2017, the full citation is available below [Parsons et al., 2017]. 


\section{References}

Abdel Aal, G., E. Atekwana, S. Radzikowski, and S. Rossbach (2009), Effect of bacterial adsorption on low frequency electrical properties of clean quartz sands and iron-oxide coated sands, Geophysical Research Letters, 36(4), doi: 10.1029/2008g1036196.

Abdel Aal, G. Z., E. A. Atekwana, L. D. Slater, and E. A. Atekwana (2004), Effects of microbial processes on electrolytic and interfacial electrical properties of unconsolidated sediments, Geophysical Research Letters, 31(12), n/a-n/a, doi: 10.1029/2004gl020030.

Atekwana, E. A., and E. A. Atekwana (2009), Geophysical Signatures of Microbial Activity at Hydrocarbon Contaminated Sites: A Review, Surveys in Geophysics, 31(2), 247-283, doi: 10.1007/s10712-009-9089-8. Atekwana, E. A., E. Atekwana, F. D. Legall, and R. V. Krishnamurthy (2004), Field evidence for geophysical detection of subsurface zones of enhanced microbial activity, Geophysical Research Letters, 31(23), doi: $10.1029 / 2004 \mathrm{~g} 1021576$.

Atekwana, E. A., D. D. Werkema, J. W. Duris, S. Rossbach, E. A. Atekwana, W. A. Sauck, D. P. Cassidy, J. Means, and F. D. Legal (2004a), In-situ apparent conductivity measurements and microbial population distribution at a hydrocarbon-contaminated site, Geophysics, 69(1), 56-63.

Atekwana, E. A., E. A. Atekwana, D. D. Werkema, J. P. Allen, L. A. Smart, J. W. Duris, D. P. Cassidy, W. A. Sauck, and S. Rossbach (2004b), Evidence for microbial enhanced electrical conductivity in hydrocarboncontaminated sediments, Geophysical Research Letters, 31(23), doi: 10.1029/2004gl021359.

Beaver, C. L., A. E. Williams, E. A. Atekwana, F. M. Mewafy, G. Abdel Aal, L. D. Slater, and S. Rossbach (2015), Microbial Communities Associated with Zones of Elevated Magnetic Susceptibility in Hydrocarbon-Contaminated Sediments, Geomicrobiology Journal, 33(5), 441-452, doi: 10.1080/01490451.2015.1049676.

Cameron, E. M., S. M. Hamilton, M. I. Leybourne, and G. E. M. Hall (2004), Finding deeply buried deposits using geochemistry, Geochemistry: Exploration, Environment, Analysis, 4, 7-32.

Corry, C. E. (1985), Spontaneous polarization associated with porphyry sulfide mineralization, Geophysics, 50(6), 1020-1034.

Davis, C. A., E. Atekwana, E. Atekwana, L. D. Slater, S. Rossbach, and M. R. Mormile (2006), Microbial growth and biofilm formation in geologic media is detected with complex conductivity measurements, Geophysical Research Letters, 33(L18403), doi: 0.1029/2006GL027312.

DeAngelis, K. M., W. L. Silver, A. W. Thompson, and M. K. Firestone (2010), Microbial communities acclimate to recurring changes in soil redox potential status, Environ Microbiol, 12(12), 3137-3149, doi: 10.1111/j.14622920.2010.02286.x.

Enright, A. M. L., and F. G. Ferris (2016), Fluctuation Analysis of Redox Potential to Distinguish Microbial Fe(II) Oxidation, Astrobiology, 16(11), 846-852, doi: 10.1089/ast.2016.1509.

Enright, A. M. L., and F. G. Ferris (2016), Bacterial Fe(II) oxidation distinguished by long-range correlation in redox potential, Journal of Geophysical Research: Biogeosciences, 121(5), 1249-1257, doi: 10.1002/2015jg003306. Essaid, H. I., B. A. Bekins, W. N. Herkelrath, and G. N. Delin (2011), Crude oil at the bemidji site: 25 years of monitoring, modeling, and understanding, Ground Water, 49(5), 706-726, doi: 10.1111/j.1745-6584.2009.00654.x. Jeon, J. H., A. V. Chechkin, and R. Metzler (2014), Scaled Brownian motion: a paradoxical process with a time dependent diffusivity for the description of anomalous diffusion, Phys Chem Chem Phys, 16(30), 15811-15817, doi: $10.1039 / \mathrm{c} 4 \mathrm{cp} 02019 \mathrm{~g}$.

Lund, A. L., L. D. Slater, E. A. Atekwana, D. Ntarlagiannis, I. Cozzarelli, and B. A. Bekins (2017), Evidence of Coupled Carbon and Iron Cycling at a Hydrocarbon-Contaminated Site from Time Lapse Magnetic Susceptibility, Environ Sci Technol, 51(19), 11244-11249, doi: 10.1021/acs.est.7b02155.

Mellage, A., C. M. Smeaton, A. Furman, E. A. Atekwana, F. Rezanezhad, and P. Van Cappellen (2018), Linking Spectral Induced Polarization (SIP) and Subsurface Microbial Processes: Results from Sand Column Incubation Experiments, Environ Sci Technol, 52(4), 2081-2090, doi: 10.1021/acs.est.7b04420.

Metzler, R., and J. Klafter (2000), The Random Walk's Guide to Anomalous Diffusion: A Fractional Dynamics Approach, Physics Reports, 339, 1-77.

Metzler, R., J. H. Jeon, A. G. Cherstvy, and E. Barkai (2014), Anomalous diffusion models and their properties: non-stationarity, non-ergodicity, and ageing at the centenary of single particle tracking, Phys Chem Chem Phys, 16(44), 24128-24164, doi: 10.1039/c4cp03465a.

Naudet, V., and A. Revil (2005), A sandbox experiment to investigate bacteria-mediated redox processes on selfpotential signals, Geophysical Research Letters, 32(11), doi: 10.1029/2005g1022735.

Naudet, V., A. Revil, and J.-Y. Bottero (2003), Relationship between self-potential (SP) signals and redox conditions in contaminated groundwater, Geophysical Research Letters, 30(21), doi: 10.1029/2003g1018096. 
Naudet, V., A. Revil, E. Rizzo, J.-Y. Botter, and P. Begassat (2004), Groundwater redox condition and conductivity in a contaminant plume from geoelectrical investigations, Hydrology and Earth System Sciences, 8(1), 8-22. Ntarlagiannis, D., N. Yee, and L. Slater (2005a), On the low-frequency electrical polarization of bacterial cells in sands, Geophysical Research Letters, 32(24), doi: 10.1029/2005g1024751.

Ntarlagiannis, D., K. H. Williams, L. Slater, and S. Hubbard (2005b), Low-frequency electrical response to microbial induced sulfide precipitation, Journal of Geophysical Research: Biogeosciences, 110(G2), n/a-n/a, doi: $10.1029 / 2005 j \mathrm{jg} 000024$.

Nyquist, J. E., and C. E. Corry (2002), Self-potential: The ugly duckling of environmental geophysics, The Leading Edge, $446-451$.

Parsons, C. T., F. Rezanezhad, amp, apos, D. W. Connell, and P. Van Cappellen (2017), Sediment phosphorus speciation and mobility under dynamic redox conditions, Biogeosciences, 14(14), 3585-3602, doi: 10.5194/bg-143585-2017.

Peng, C. K., S. V. Buldyrev, S. Havlin, M. Simons, H. E. Stanley, and A. L. Goldberger (1994), Mosaic organization of DNA nucleotides, Physical Review E, 49(2), 1685-1689, doi: 10.1103/PhysRevE.49.1685. Personna, Y. R., D. Ntarlagiannis, L. Slater, N. Yee, M. O'Brien, and S. Hubbard (2008), Spectral induced polarization and electrodic potential monitoring of microbially mediated iron sulfide transformations, Journal of Geophysical Research: Biogeosciences, 113(G2), n/a-n/a, doi: 10.1029/2007jg000614.

Revil, A., C. A. Mendonça, E. A. Atekwana, B. Kulessa, S. S. Hubbard, and K. J. Bohlen (2010), Understanding biogeobatteries: Where geophysics meets microbiology, Journal of Geophysical Research, 115, doi: $10.1029 / 2009 j \mathrm{jg} 001065$.

van Bochove, E., S. Beauchemin, and G. Theriault (2002), Continuous Multiple Measurement of Soil Redox Potential Using Platinum Microelectrodes, Soil Science Society of America Journal, 66(6), 1813-1820.

Williams, K. H., S. S. Hubbard, and J. F. Banfield (2007), Galvanic interpretation of self-potential signals associated with microbial sulfate-reduction, Journal of Geophysical Research: Biogeosciences, 112(G3), n/a-n/a, doi: $10.1029 / 2007 j \mathrm{jg} 00440$.

Williams, K. H., D. Ntarlagiannis, L. D. Slater, A. Dohnalkova, S. S. Hubbard, and J. F. Banfield (2005), Geophysical imaging of stimulated microbial biomineralization, Environ Sci Technol, 39(19), 7592-7600. Williams, K. H., A. L. N'Guessan, J. Druhan, P. E. Long, S. S. Hubbard, D. R. Lovley, and J. F. Banfield (2010), Electrodic voltages accompanying stimulated bioremediation of a uranium-contaminated aquifer, Journal of Geophysical Research: Biogeosciences, 115(G2), n/a-n/a, doi: 10.1029/2009jg001142. 